\title{
A LÍNGUA KARAJÁ: EMPRÉSTIMOS LINGUÍSTICOS
}

\section{Leandro Lariwana Karajá}

Formador Pesquisador

\section{RESUMO}

A pesquisa da língua iny rybè feita em quatro aldeias Karajá, situadas na Ilha do Bananal, nesta pesquisa foram entrevistadas as mulheres, o objetivo é comparar a fala das mulheres com a dos homens que usam muito o empréstimo da língua portuguesa, porém as mulheres são mais conservadoras. A língua iny está mais viva com elas, não importa onde elas estiverem quer na cidade ou na aldeia o uso da língua iny está sempre em primeiro lugar.

PALAVRAS-CHAVE: Empréstimo. Bilinguismo. Língua karajá. Língua portuguesa.

\section{TURYBÈNABUTÈ}

Iny rybè-my tyyrti relere inaubiòwa hãwa-ki ijataho bdebutèhèkỹ-ki roimyhỹre, kaki hãwyy mahãdu-ò lỹỹraxi relere, hãbu mahãdu rybèwna widèè rekeitxènanyre, hãbu mahãdu sõèmy tori rybè riuhèmyhỹre, hãwyy mahãduxe aõkõre iny rybè aõnityhymy riuhèmyhỹrènyre hãbu-rbi tii boho iyn rybè-di irutyhymy ratximyhỹrènyre, aõtxile tiki ratxirèny-ki iny rybè hyy riuhèmyhỹrènyre, torina-ki aõbo da iny hãwa-ki aõbo, iny rybè tiièmy koki tai reny roimyhỹre.

RYBÈ WÊRYNA: Rybèhuòtè. Inatximyrybè. Iny rybè. Tori rybè. 


\section{ESTUDO COM MULHERES INY}

A pesquisa com mulheres Karajá foi na aldeia Fontoura, onde percebi que as mulheres são mais difíceis de usar o empréstimo linguístico e invasão linguística do que os homens. Primeiro, procurei pesquisar as mulheres de duas aldeias: JK e Santa Isabel do Morro. As duas localizam-se no Estado do Tocantins, no município da Lagoa da Confusão. De acordo com a pesquisa, descobri que as mulheres, que são mais domésticas, ou seja, vivem mais para cuidar do lar, da família, e que não têm estudo, preservam mais a língua iny rybè (fala Karajá). No seu dia a dia estão sempre usando a língua Karajá. Em qualquer lugar que elas estejam, na aldeia, na cidade, vajando etc. Essas mulheres são artesãs. O mais incrível é que elas negociam com seus clientes, os compradores de artesanato, em sua língua materna. Elas conseguem fazer com que esses compradores entendam sua linguagem.

Nessa negociação, os toris (não-indígenas) falam com essas mulheres em português, e elas respondem em iny rybè. Certa vez eu estava no supermercado, e uma senhora iny (Karajá) estava conversando com o comerciante em iny rybè. Fiquei boquiaberto quando ela falou: "tiwsebo rasiranyra" (quanto faltou?). O mais interessante é que o comerciante estava respondendo tudo direitinho. Refleti muito sobre esse evento comunicativo. Pensei: por que eu não faço assim como as mulheres? Essas mulheres estão valorizando a nossa língua diante da sociedade envolvente sem se preocupar se eles vão entender ou não. Elas mostram que a língua iny tem o seu valor como qualquer língua no mundo.

Outra atitude linguística bem interessante dessas mulheres. Quando elas se deparam com coisas novas, novas tecnologias ou qualquer coisa que não tem nome na língua iny, se recusam a falar o nome dos produtos em português, fazem empréstimo, uma adaptação fonológica, como, por exemplo; pão "baõ", picolé "bikòlè", computador "kõbutadu". Esses são alguns exemplos. A pergunta é: será que elas falam assim porque não conseguem dominar o português ou por ter orgulho pela Karajá? Só sei que essas mulheres são verdadeiros exemplos para a sociedade do povo Karajá. A atitude delas é de amor pela sua língua. 
Já as mulheres que têm um pouco de estudo ou são empregadas em algum órgão governamental, como, por exemplo, na FUNAI, na FUNASA e na SEDUC, adotam outra atitude linguística. Essas mulheres dominam o português e deixam a língua portuguesa invadir a língua iny. A consequência dessa atitude é a invasão linguística da língua portuguesa na comunicação iny até mesmo dentro da aldeia onde não deveria ter nenhuma necessidade de se falar assim. Essas mulheres estão no rumo do caminho dos homens. Ao contrário das mulheres que não têm estudo, quando estão dialogando com os não-índios falam normalmente em português da mesma forma que os homens. Parece que têm vergonha de usar o empréstimo linguístico. Parece que usar a invasão linguística é como enfeitar a língua Karajá.

O problema é que dessa forma estão ajudando as crianças a falarem uma nova língua: uma mistura de língua, português e Karajá. Como sempre essa missão da conscientização linguística é da escola. Nós os professores temos que levar para dentro da escola, posteriormente para toda comunidade, uma política de valorização da língua materna. A responsabilidade é grande. Não é fácil a missão da descolonização linguística. Muitas comunidades têm a ilusão de que, falando português, teremos um futuro brilhante e que estudar a própria língua materna só atrasa o estudo das crianças. $\mathrm{O}$ estudo da língua materna não serviria para nada diante da sociedade não-indígena. Para eles a língua iny só serve para falar na aldeia. Contrariando essa concepção, a maioria das mulheres mostra que a língua iny é para dialogar com qualquer ser humano. Se todos nós pensássemos como elas, de maneira nenhuma deixaríamos de falar a língua iny rybè.

Seríamos como o povo nativo do Alaska. Esse povo valoriza muito a língua nativa deles, tanto é que o ofício feito por eles para o governo é na própria língua deles, o governo se encarrega de arranjar um intérprete. Por que nós não fazemos desta forma? Por que nós nos submetemos à sociedade envolvente? Ao nos submetermos, desvalorizamos a nossa própria língua. Devemos ter a mesma atitude das mulheres já citadas. Elas mostraram para mim grande força linguística. Se elas conseguem comunicar com qualquer tori na língua materna, nós os homens podemos seguir o 
mesmo caminho e tenho certeza que seriam mais bonito os eventos comunicativos. Esta foi a minha pesquisa com as mulheres de duas comunidades.

\section{EMPRÉSTIMO LINGUÍSTICO KARAJÁ}

Depois de ter pesquisado várias pessoas, procurei pesquisar as crianças de duas aldeias, a JK e Santa Isabel do Morro. A pesquisa foi com as crianças de 5 a 10 anos de idade. Observando o modo da fala dos alunos da escola estadual indígena krumare, da aldeia JK, situada na Ilha do Bananal-TO, município da Lagoa da Confusão, e também com as crianças da maior aldeia da Ilha do Bananal, Santa Isabel do Morro, situada no mesmo município. Na minha observação, a língua iny é compatível à língua portuguesa, pois esta se adapta facilmente à iny rybe, o que aumenta mais a minha preocupação com relação à invasão da língua portuguesa na iny rybè. Se a comunidade não percebe isso, a responsabilidade é nossa, me refiro aos novos licenciados Karajá, em Ciências da Linguagem da UFG. Precisamos começar política linguística forte na escola e depois levá-la para as comunidades em todas as aldeias dos Karajá, conscientizando do perigo de extinção da língua Karajá.

Entre as crianças a invasão linguística acontece por meio da televisão. As crianças começam a falar imitando a fala dos personagens da televisão e outros. Antigamente os iny não faziam isso. Eles sempre faziam empréstimos semânticos, mas fazendo adaptações fonológicas, como, por exemplo, "nieru" (dinheiro), e que hoje em dia está sendo deixado de lado pelas crianças e jovens ou até mesmo por alguns professores, o que é mais preocupante. Muitos falam logo "dinheiro" como é em português.

Muitas adaptações fonológicas feitas nas palavras emprestadas não são percebidas pelos “tori”. Alguns são totalmente difíceis de serem percebidas. São os empréstimos mais antigos, ainda do tempo do período colonial, como, por exemplo, a palavra "pote", que foi fonologicamente adaptada para "boti" ou "butxi", dependendo da região Karajá. Galinha que se tornou "hãniè" em iny rybè. Este último empréstimo não foi percebido nem por pesquisadores da língua Karajá. Está totalmente modificado e adaptado perfeitamente 
à fonologia da língua Karajá. Muitos dos meus colegas negam que "hãniè" seja empréstimo semântico da língua portuguesa, mas cheguei à conclusão que galinha é uma ave de outro continente, vindo para o Brasil no período colonial.

Vaca e o cachorro receberam o nome de modo diferente; vaca "broreni", cachorro "ijòròsa". A tradução literal dos dois é, respectivamente, semelhante a veado, raposa malhada. Existe na língua iny um morfema "ni", que indica semelhante a, ou seja, brorè (veado) ni (semelhante a veado) = vaca. Ijòrò (raposa) ijòròsa (raposa malhada ou de cores diferentes)=cachorro.

Cavalo e garrote receberam, como galinha, adaptações fonológicas, mas são mais nítidas. Qualquer um pode perceber as modificações do português para o iny: cavalo "awaru, kawaru", falas masculina e feminina, respectivamente. Garrote "aròti, karòti", nas falas masculina e feminina, respectivamente. Se tivesse algum animal parecido com cavalo provavelmente usaríamos o morfema de semelhante a. Do mesmo modo com o nome galinha (haniè), que só foi modificado por não ter uma ave semelhante.

"Nieru" (dinheiro), antes era falado desta forma, como no enunciado: "wanieru tahe?" "cadê o meu dinhero?" Agora a nova geração fala o nome dinheiro em português, mais ou menos desta forma "wadinheiro tahe?".

O enunciado fica composto com duas palavras em Karajá e uma em português. Em minha observação durante a pesquisa com as crianças, percebi que existem algumas vogais que estão presentes frequentemente no dia a dia da fala das crianças, ou melhor, por quase todas as pessoas da comunidade. A mais usada é a vogal é [ə], como, por exemplo, quando se fala desta forma: "bdèteheini-ò", a tradução seria mais ou menos assim, "veja só, olha". A palavra tradicional Karajá seria assim: "bdèteheini-he". O "he" está sendo deixado de falar pelas novas gerações. Eu chamo isso de invasão linguística. Entram na língua Karajá sem necessidade. Inúmeras palavras vindas do português estão empurrando as palavras Karajá para fora de sua língua, e ocupando o lugar dessas.

Entre as meninas está acontecendo a mesma coisa. Parece que as crianças se recusam a falar o que era falado na antiguidade. É para se mostrar que sabe falar muito bem a língua portuguesa. 
Essa confusão linguística é lamentável. É lamentável ver o meu próprio povo deixando de falar a rica língua que temos. Outro dia eu estava observando os alunos na hora do lanche. Desta vez é sobre o alimento, por exemplo, ao invés de falar "rùùbrèè ou rùkùbrèkè (melancia), falas masculina e feminina, respectivamente, estão falando "melanciá". No lugar de falar "brorenidè" (carne de vaca) estão falando "carne". O mesmo acontece com a carne de frango, que é "hãnièdè"; falam laranja, ao invés de "rarajỹ".

Pesquisei criança no rio Araguaia. Nossas crianças gostam do rio, crianças Karajá adoram pescar, mas os nomes dos peixes também estão sendo esquecidos por elas. O nome das tralhas de pesca estão usando a palavra correta. Muitos peixinhos estão sendo trocados seus nomes em iny para o português, como, por exemplo: "hãriwa" por pacu. A palavra pacu tem origem Tupi; "myriweni" trocado por sardinha; "hãriìri" por caranha, "bywì" por piau e etc. São palavras de origem tupi, mas não são da língua Karajá.

Existem muitas coisas para descobrir ainda. Esses são apenas alguns exemplos que consegui coletar através da convivência com as crianças, dialogando com elas, brincando, conquistanto a confiança e amizade delas, sem nunca procurar repreendê-las. Procuro mostrar amigavelmente para não constrangê-las e não confudir as cabecinhas delas.

Como coloquei, a escola é único lugar onde pode começar uma política linguística. Hoje conheço o quanto é importante lutar pela manutenção da língua materna de todos os povos minoritários, senão daqui há alguns anos não falarão mais suas línguas. Os Iny pode não falar mais nossa língua iny. A luta não é fácil, tem que ter a união de todos, não só das comunidades falantes dessa língua, tem que ser lado a lado com aqueles que lutam pelas causas indígenas, pois eles que abriram a minha nova visão na luta contra a invasão linguística. Pois aqui deixo a minha gratidão por todos aqueles que colaboraram com esta pesquisa. Acredito que foi suficiente nós meditarmos sobre a questão sociolinguística da língua Karajá. Até a próxima pesquisa. 


\section{A LÍNGUA KARAJÁ: EMPRÉSTIMOS LINGUÍSTICOS}

Através da pesquisa tive a noção do que é empréstimo linguístico, assim comecei a perceber que as línguas faladas em todas as partes do mundo ampliam-se, se enriquecendo no contato entre povos diferentes, cada qual com as suas histórias diferentes para contar. Da mesma forma, aconteceu e acontece com os Karajá. Na minha pesquisa com as diferentes falas da língua "INY" (como os Karajá autodenominam sua língua materna), percebi que existem muitos empréstimos, os quais entraram por meio de línguas indígenas, como, por exemplo, dos Tapirapé e dos Kaiapó. Esses dois povos tiveram contato mais frequente com os Karajá e não, raramente, hostis. Além destes também tivemos contatos com os povos que hoje só existem nas nossas lembranças, que foram extintos provavelmente por causa do conflito. São eles: Wabinore, Werehina, Wèrè e Ijèwèhè. Muitos Karajá acreditam que existem dentre os Karajá os descendentes destes povos e algumas palavras pertencem a eles.

As línguas que entraram na língua Karajá hoje estão totalmente adaptadas, somente através da pesquisa podemos perceber as diferenças. Para eu entender mais desse tema fiz a pesquisa sobre a língua portuguesa, língua que sempre pensei que era inabalável, impossível de ser invadida por qualquer outra língua, porém através da pesquisa, entendi que o léxico de todas as línguas se renova.

As novas palavras, os neologismos, podem ser criados com elementos da própria língua, formando derivados e compostos, sobretudo, ou com elementos oriundos de outros idiomas, denominados empréstimos. Como já coloquei, o empréstimo linguístico é tão antigo quanto a história da humanidade, da mesma forma acontece com as línguas indígenas. A língua portuguesa sofreu a invasão linguística, porém seus falantes souberam adaptar a própria língua que hoje a maioria dos falantes do português não percebe que a sua língua veio de várias outras faladas por vários povos.

Através da pesquisa pude ver os empréstimos na língua portuguesa, mas isso não a afetou, mas a enriqueceu, formando novas palavras. Como, por exemplo, de origem Germânica são numerosos 
substantivos, adjetivos e verbos que apresentam como particularidade fonética a transformação do W (inicial) em guerra (werra), guisa (wise). Esses são empréstimos mais antigos da língua portuguesa. Já no português brasileiro, encontrei as seguintes palavras; dos escravos africanos foram introduzidas as seguintes palavras que enriqueceram o português do Brasil: camundongo, angu, xangô, berimbau, dendê, senzala, macumba, tutu, estas são algumas designações africanas. Da América espanhola, elementos da língua pré-colombiana vieram para o Brasil por meio do espanhol: chocolate, xícara, lhama, cacau, tomate, canoa, condor, e etc. Estas são faladas aqui no Brasil e são termos não encontrados no português do Portugal, segundo o autor (Houaiss, 1999). Além dessas existem várias palavras de outros povos que estão totalmente adaptadas na língua portuguesa, e só é percebível através da pesquisa.

Segundo o autor Houaiss, o empréstimo linguístico revela a face histórica do empréstimo na língua portuguesa, mostrando como o idioma recebeu elementos das línguas faladas pelos vários povos: Celtas, Germânicos, Árabes, dentre outros que passaram pela Península Ibérica. No Brasil, a língua portuguesa recebeu das línguas indígenas muitas palavras, como, por exemplo: mangaba, jaguar, jacaré, piracema, e entre outras, que são de origem tupi-guarani. Pouco se sabe das línguas do Tronco Macro-Jê na língua portuguesa brasileira.

De acordo com o autor citado acima, esta também é minha opinião, um povo ao assimilar a língua de outro (não os empréstimos linguísticos), torna-se facilmente manipulável, acabando por perder sua identidade, sua independência e, com ela, sua liberdade. De acordo com Pimentel da Silva (2009), uma coisa é empréstimos linguísticos, outro é empréstimos de línguas. É isso que está acontecendo com as línguas dos povos indígenas brasileiros e de todo o mundo.

Hoje através da pesquisa estou percebendo o quanto à língua Karajá está correndo o risco de ser extinta em um período muito curto, se não tomarmos medidas. Somente os Karajá podem ajudar a sua língua se manter viva. Eu me sinto responsável para passar essa realidade para meu povo. $\mathrm{O}$ peso da responsabilidade está sobre mim, pois estou estudando na licenciatura. Entendi como uma língua 
morre.

A política linguística de valorização da língua materna nativa deve partir da própria família e depois levar para a escola. Hoje as crianças da minha escola estão superinteressadas na questão de empréstimo linguístico, como também sobre a invasão linguística. Acho interessante quando os alunos ficam discutindo a respeito, um corrigindo outro, e se divertindo com isso. Hoje eles já percebem a diferença, mas o desafio é levar essa política linguística para todas as escolas do povo Karajá.

\section{CONSIDERAÇÕES}

O léxico da língua Iny está mudando. A cada geração vem um novo jeito de falar. A geração de hoje está introduzindo muitas palavras da língua portuguesa, o que eu não chamo de empréstimo e sim invasão linguística. Se nós falantes da língua Iny não fizermos nada, daqui há

100 anos não vamos falar mais a língua Iny, e, sim, uma nova língua, resultado de uma mistura com a língua portuguesa. Para não acontecer isso, nós, estudantes da educação intercultural, temos que travar uma batalha contra a invasão linguística que vem diretamente da língua portuguesa.

Entre as falas dos jovens, peguei alguns exemplos de palavras do português que mais entram na Iny durante o diálogo dos jovens Karajá. Coloquei as mais frequentes durante a conversa:

$>\quad$ diarỹ wiji wasorte-my atxirèri

$>$ tiiboho wadi riwakuidany-my roiremyhỹwiji três ano ratxireri tiu tii rihesovenyõtyhy

kaawè nafocionanymyhỹde?

\section{Tradução:}

$>\quad$ hoje eu estou com sorte 
eles cuidavam de mim

hoje ele está com três anos

ele nunca vai resolver

este aqui esta funcionando?

\section{Língua padrão Iny (as falas certas são as seguintes):}

$>\quad$ diarỹ wiji wabdèòbymy watxireri

$>\quad$ tiiboho wadi riwaywinymy roiremyhỹ

wiji inatão-my iwyra ratxireri

tiu tii riywinyõtyhy

kaawè dèalemyhỹde?

Os empréstimos que vêm das línguas indígenas, como é o caso da língua Tapirapé, um povo vizinho, que no passado existia um tipo de comércio entre eles e os Karajá, provavelmente nesse tempo, palavras de uma língua foram emprestadas para outra. Hoje em dia, as duas culturas são muito semelhantes, algumas palavras também são parecidas, com os mesmos significados, adornos usados também são iguais. Seguem exemplos de algumas palavras parecidas e com os mesmos significados encontrados em Tapirapé e Karajá.

\begin{tabular}{|l|l|}
\hline Língua Tapirapé & Língua Karajá \\
\hline Pãtawari & Bijawari \\
\hline Wakarexapapyyka & $\begin{array}{l}\text { (masculino) waarere } \\
\text { (feminino) wakaree }\end{array}$ \\
\hline Xarawe & Tarawe \\
\hline
\end{tabular}


Estas são algumas palavras que tem nas duas línguas: Karajá e Tapirapé. O Tapirapé, ao contrário do português, não prejudicou a língua Iny. Ao invés disso, enriqueceu o léxico da língua Iny. Os empréstimos que chegam à língua Karajá vindos do português quase sempre tomam lugar de uma palavra na nossa língua. Muitas vezes esses empréstimos tiram dos indígenas a possibilidade de criar palavras novas para nomear realidades novas. Desse modo, os falantes vão se tornando bilíngues passivos, aceitando a colonização linguística imposta pelos falantes da língua portuguesa. A instituição que mais provoca essa situação é a escola. Neste contexto, dá-se todo prestígio à língua portuguesa.

Seguem alguns exemplos de empréstimos linguísticos de línguas indígenas que estão na língua Karajá:

\section{Empréstimos do Tapirapé para o Karajá}

\section{Produtos de Roça}

$\begin{array}{llc}\text { Karajá } & \text { Tapirapé } & \text { Tradução } \\ \text { Ara }(\mathrm{FM})^{1} \text { Kara }(\mathrm{FF}) & \text { Kara } & \text { cará } \\ \text { Aõna }(\mathrm{FM}) \text { anona }(\mathrm{FF}) & \text { anona } & \text { abacaxi } \\ \text { Òmyta }(\mathrm{FM}) \text { kòmyta }(\mathrm{FF}) & \text { komanã } & \text { feijão } \\ \text { Brurè }(\mathrm{FM} \mathrm{e} \mathrm{FF)} & \text { xỹpororè } & \text { enxada }\end{array}$

Esses são alguns dos exemplos que mostram o intenso contato dos Karajá com os Tapirapé. Há muitas trocas entre esses dois povos que apontarei de acordo com o desenvolvimento de minha pesquisa.

\section{Empréstimos do Kaiapó para o Karajá}

Karajá

${ }^{1} \mathrm{FM}$ - fala masculina e FF - fala feminina

Kaiapó 
Além dos nomes próprios, muitas músicas Kaiapó estão adaptadas à cultura Karajá. Existe muito da cultura Karajá nos Kaiapó como também nos Tapirapé. De acordo com o andamento da pesquisa, apresentarei mais dados que serão importantes para o conhecimento dos jovens da história de seu povo com outros povos indígenas. A escola também ganhará à medida que terá acesso a outras histórias, ou seja, a história de contato do Karajá com outros povos. Este estudo poderá contribuir também para a melhoria do currículo da escola e também para o entendimento do bilinguismo do povo Karajá.

Agora a língua Karajá está à beira da extinção em algumas aldeias, on de ela não é mais usada como a primeira língua, como é o caso da maioria das pessoas da aldeia Buridina, situada em Goiás, e do povo de Xambiowa, que já não falam mais a sua língua materna, mas estão em processo de revitalização.

Essa é um pouco da experiência que adquiri durante a minha pesquisa com os jovens das aldeias e entre os universitários da Licenciatura Intercultural - UFG.

Assim finalizo o meu estudo.

\section{REFERÊNCIAS}

PIMENTEL DA SILVA, Maria do Socorro. "Fronteiras etnoculturais: educação bilíngue intercultural e suas implicações”. ROCHA, Leandro Mendes; BAINES, Stephen Grant. (coordenadores). Fronteiras e espaços interculturais. Transnacionalidade, Etnicidade e Identidade em regiões de fronteira. Goiânia: Editora da UCG, 2008. 107-117pp.

Reflexões sociolinguísticas sobre línguas indígenas ameaçadas. Goiânia: Editora da UCG, 2009. 